\title{
A Corpus-Based Study on the Use of Feelings and Emotions Vocabulary by Male and Female EFL Learners
}

\author{
M. Pınar Babanoğlu \\ Department of Translation Studies, Kahramanmaras Sutcu Imam University, Kahramanmaras, Turkey
}

\section{Email address:}

pinarbab@hotmail.com

\section{To cite this article:}

Muzaffer Pınar Babanoğlu. A Corpus-Based Study on the Use of Feelings and Emotions Vocabulary by Male and Female EFL Learners. International Journal of Language and Linguistics. Vol. 3, No. 4, 2015, pp. 203-209. doi: 10.11648/j.ij11.20150304.12

\begin{abstract}
Research on the relationship between gender and language has been a challenging inquiry as being closely related to social issues. Particular interest has mainly been in whether women and men use the language differently. Also gender and language related studies have mainly concentrated on the identification and characterization of male/female language and how language users speak and write in ways that reflect their genders. For instance, Newman, Groom, Handelman and Pennebaker (2008) state that women use more words related to psychological and social processes (emotions, sensations, friends, family, etc.) whereas men referred to object properties and impersonal topics. In language learning, besides it is generally believed that females learn and speak a language better and faster (Zhuanglin, 1989), it is still a mystery to what extend males and females express their genders when using a foreign language. This particular corpus-based study investigates gender differences in using feeling and emotion vocabulary in argumentative essays by EFL learners. Results indicate that, unlike the related statements about gender and language in general, male learners tended to use more feeling and emotion vocabulary than female learners in their written L2 productions. In addition, learners from different L1 backgrounds displayed similar tendency in categorical usage of emotional words.
\end{abstract}

Keywords: Learner Corpus, Gender Differences in Language, Feelings and Emotions Vocabulary

\section{Introduction}

Relationship between gender and language has always aroused interest as its having the potential of ascertaining sex differentiation, especially the issue of whether women and men use the language differently. As a factor of sociolinguistics, most of earlier literature on gender and language studies has concentrated on the identification and characterization of male/female language and how language users speak and write in ways that reflect their genders (Labov, 1966; Trudgill, 1972; Lakoff, 1975; Coates, 1998). For instance, a characterization by Lakoff (1975) suggests some diversifications such as women use more tag questions, more correct grammar, more intensifiers and even more empty adjectives than man such as 'charming' and 'nice'. Holmes (1998) draws attention to a range of sociolinguistic universal keynotes differing in gender such as women and men develop different patterns of language, women tend use linguistic devices that stress solidarity more often than men do and also women are stylistically more flexible than man. Haas (1979) states that men use non-standard forms talk more about sports, money, business, frequently refer to time, space and quantity and physical movements. Women are polite, supportive, talk more about family and home, and they use more words implying feeling, evaluation, interpretation and psychological state. In terms of emotive issues from a cognitive perspective, a study on gender difference states that women significantly use more emotional words than man (Goldsmidt \& Weller, 2000). Corpus approach is rather recent application in language and gender relation research, yet corpus methodology may provide empirical and natural language data source for better understanding for both sociocultural and sociolinguistic investigations in gender studies.

Newman, et al. (2008) investigated 14,000 text samples from corpus-based 70 studies over a 22 years period (19802002) and found that women use more words related to psychological and social processes such as emotions, sensations, friends, family, etc. whereas men referred to object properties and impersonal topics. Accordingly, Baker (2014) investigated the phrase 'I love you' in BNC corpus' 
transcriptions of about 10 million words and he found that females used it three times as much as males in the spoken part of BNC. In language learning, a general belief was that male and female are born with different linguistic advantages; female learn to speak earlier than male and they also learn a language faster and better (Zhuanglin,1989).

This study investigates the uses of feeling and emotion words in written productions of female and male EFL learners. The linguistic aspects of this study are feeling and emotion words such as 'happy', 'disappointed', 'afraid', 'nervous', and 'grateful' are used to describe emotional state in written discourse. Three learner data groups were utilized in the study as Turkish (TICLE), Japanese (JPICLE) and Spanish (SPICLE) from International Corpus of Learner English (ICLE). As for native English data for comparison with learner, data base from native English parts of Michigan Corpus of Upper Level Students (MICUSP) papers were included to the examination. Data collection procedure of EFL learners is based on identification of selected emotion and feeling words throughout three corpora by means of Sketch engine software (Kilgariff, et al., 2004). L2 group comparisons of frequency and log-likelihood measurement between female and male learners were utilized for quantitative process of the analysis. Research questions are as follows:

RQ.1. Is there significant difference in the frequency of feeling \& emotion vocabulary between female and male groups of EFL learners and of native English speakers?

R.Q.2. What type of feeling \& emotion vocabulary do male and female EFL learners prefer to use?

This present study limited to the number of the words of texts of male and female EFL learners and native English speakers. The linguistic items in the study consisting of a variety of syntactic categories as verbs, adjectives, nouns, etc but restricted to four semantic categories as anger/hate, happiness/joy/caring, depression/sadness and fear.

\section{Background of the Study}

Gender and language research mostly favour the idea of potential difference in language use between men and women. Accordingly, such gender difference can be argued in second language learning as well. It is assumed that the second language acquisition is influences by factors of individuals differences such as age, aptitude, motivation, learning style and sex. Previous gender related L2 literature suggest that gender can have a significant effect on learning a language (Oxford, 1993; Young and Oxford, 1997), in addition, sex and gender based studies have found that females tend to present more motivated and positive attitudes to L2 learning and use a wider range of learning strategies, especially social ones (Zafar and Meneeakshi, 2012; Zeynali, 2012).

In second language research field, researchers as Rintell (1985) and Graham (2001) who studied emotion words in interlanguage reported some degree of deficiency in the use and judging of emotion words. Another research the use of emotion words has been correlated not only to just gender variations but also to proficiency level, socio-cultural competence and linguistic devices by Dewaele \& Pavlenko (2002) and they concluded that gender is not the only key variable determining the amount and the range of emotion words used in a speech. Additionally, Koçoğlu (2013) examined gender differences on effective communication strategies of EFL learners and native English speakers, Hayati et al. (2014) investigated refusal strategies between male \& female EFL students. Although the majority of previous research were conversational based, however, as Xiao \& Tao (2007) claims that gender differences from women and men also vary from speaking to writing and it is therefore worth to examine the written contexts considering gender differences. Chen (1996) studied writing errors in male \& female EFL learners using computer generated error feedback and concluded that male EFL learners did have higher error rates than females. Gholami (2011) examined task-bases activities between male and female EFL learners and found no significant gender difference. Shehadeh (1999) investigated cross-gender conversation between native and non-native speakers and suggested that men and women tend to use conversation for different purposes, men use conversation as a way of promote their performance/production ability whereas women utilize the conversation to promote their comprehension ability. Shehadeh concluded as EFL/ESL teachers should mentor the classroom interaction in order to create equal opportunities for both females and males (1999).

To summarize, most of general former gender and language literature exist in the favour of women are more emotional and use more emotionally expressive and eager to discuss emotional subjects whereas men are accepted concentrate more on communicative aspects. On the other hand, some research reported no difference in emotion related talk in interlanguage (Rintel, 1984) while more recent research (Dewaele and Pawlenko, 2002) found that although females use a wider variety of emotion vocabulary, no significant difference among interlanguage speakers of English found in the use of emotion vocabulary due to gender factor.

\section{Methodology}

Three EFL corpora used in the study from worlds' widest learner corpus; International Corpus of Learner English (ICLE), consisting of 3.7 million words from argumentative essays of EFL learners from 16 different L1s. Turkish (TICLE), Japanese (JPICLE) and Spanish (SPICLE) subcorpora were utilized as parts of ICLE corpus. Texts in each sub-corpus were divided as Male and Female users. Native English data gathered from Michigan Corpus of Upper Level Students (MICUSP) female and male students' argumentative essays. Distribution of corpora used in the study is as presented: 
Table 1. Distribution EFL and Native English Corpora.

\begin{tabular}{llll}
\hline Corpora & & Number of texts & Number of words \\
\hline & TICLE_M & 50 & 38586 \\
& TICLE_F & 52 & 37925 \\
EFL & JPICLE_M & 50 & 33624 \\
& JPICLE_F & 51 & 32819 \\
& SPICLE_M & 34 & 29906 \\
& SPICLE_F & 39 & 29769 \\
Native & MICUSP_M & 15 & 38318 \\
English & MICUSP_F & 19 & 38197 \\
\hline
\end{tabular}

$\mathrm{F}=$ Female data $\quad \mathrm{M}=$ Male data

Linguistic items (Feeling \& Emotion vocabulary) were identified in each male/female EFL sub-corpus via Sketchengine software. Then calculated frequencies of Feeling \& Emotion vocabulary were compared as:

Male EFL corpora vs. Female EFL corpora by Loglikelihood (LL) ratio of frequencies are measured to test the statistical significance of differences. LL ratio is a useful measurement for corpus comparison as it calculates the frequencies and number of all words in corpus (Kilgariff, et al., 2004). LL ratio identifies the differences between two corpora and determines whether that difference is significant and also specifies in which group the overuse and underuse (http://ucrel.lancs.ac.uk/tools.html).

Four sets of feeling \& emotion words in different lexical structures (verb, adjective, noun, etc) were utilized in the study (Mclaren, 2013):

Anger/Hate :angry, mad, wild, aggressive,..

Joy/Happiness : love, happy/happiness, hope,..

Depression/Sadness : sad, hopeless, sorry, worried, ...

Fear : afraid, terrified, shocked, ...(see Appendix)

\section{Results and Discussion}

The initial analysis was made on the comparison of male and female users in order to elicit a possible quantitative difference between genders. Figure 1. shows the overall frequency of feeling \& emotion vocabulary by male and female users:

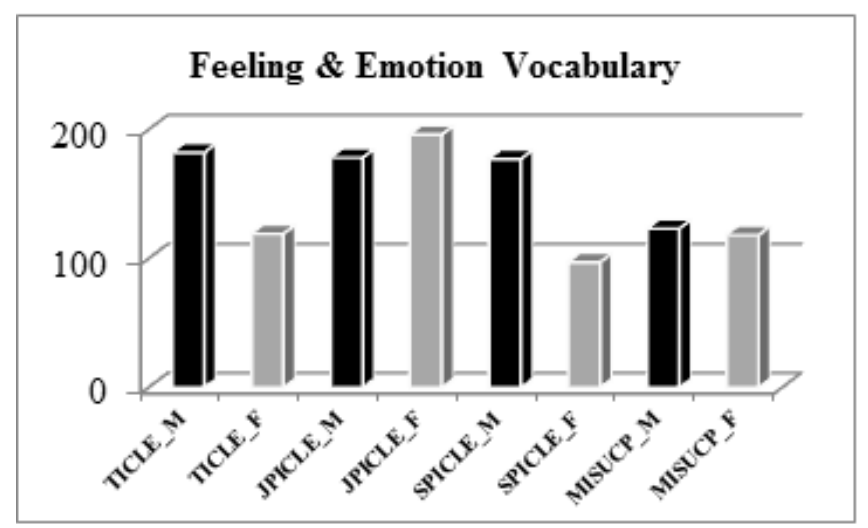

Figure 1. Overall frequency of feeling \& emotion vocabulary used by male and female students in their argumentative essays.

At the first sight, there seems a frequency difference between male and female students in the use of emotional vocabulary that needs a statistical measurement.

In order to see each male and female group performance in using feeling \& emotion vocabulary, group frequencies are presented in Figure 2 below. When each groups' frequency of emotional vocabulary considered, males in all groups seem to have higher rates. Turkish, Japanese and Spanish male groups showed a similar performance except for native English male group which has even higher frequency than some female groups. All female EFL and native English students close each other in overall frequency, Japanese EFL Female learners only come to the forefront against not only their native counters but also all other male groups.

Overall frequency difference occurred between two genders is to be tested between and within all student groups through Log-likelihood ratio to find out whether it is statistically significant shown in Table 2.:

Table 2. Log-likelihood results of frequency difference between total male and female students.

\begin{tabular}{llll}
\hline & LL ratio & LL ratio & LL ratio \\
\hline F\&E Vocabulary & $+17.05^{*}$ & +0.09 & $+14.98^{*}$ \\
\hline
\end{tabular}

$* \mathrm{p}<0.05$ (critical value: 3.84 )

+ indicates overuse in the first corpus relative to the second corpus

- indicates underuse in the first corpus relative to the second corpus

Log-likelihood results indicated that frequency difference between EFL male and female learners is significant with +17.05 in favour of males which means male learners used feeling \& emotion words statistically more than females. Native speakers do not yield a significant difference in respect of gender. Overall male and female performance outcome expressed +14.98 of overuse by all male groups that is a statistical prove of male students use more emotion and feeling vocabulary in their argumentative essays than females no matter their native language or they are being an EFL learner.

Statistics of categories of feeling \& emotion words were calculated in order to see the emotional word preference of users and shown in Figure 3:

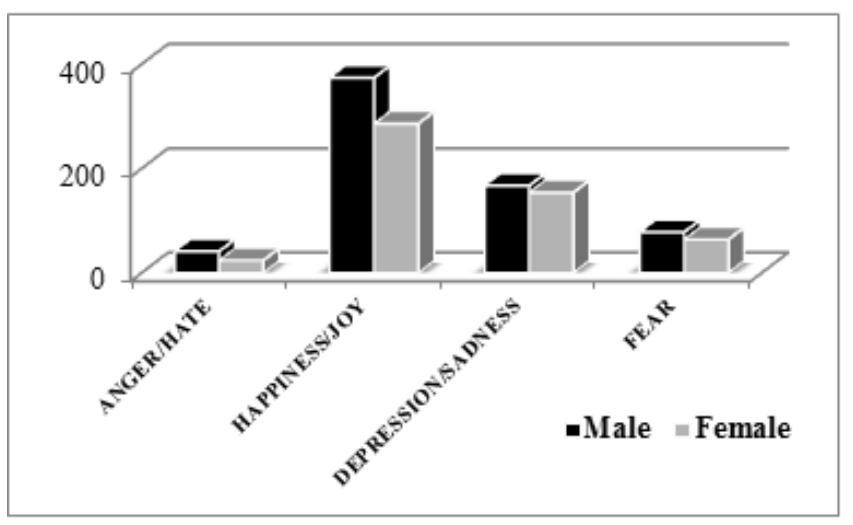

Figure 2. Categorical statistics of feeling \& emotion words used by male and female students in their argumentative essays.

As can be seen, mostly used feeling \& emotion words are happiness/joy words such as love, happy, etc. Second 
emotional word category is depression/sadness words like sad, hopeless, miserable, etc. Fear words like unsure, scare, and afraid and anger words like hate, dislike, hostile are lesser used emotional vocabulary groups. In sum, regardless of their genders, all male and female student groups tended to use positive emotion words most. Female vs. male comparison of happiness and depression words revealed close results at Figure 2. above so that individual evaluation may need different explanation as for poles apart positions of happiness and depression words in total as shown in Figure 3. Being semantically antonym of each other, when happiness/joy and depression/sadness related words compared each other in all groups, results revealed that happiness/joy words seem dominant in frequency in almost all groups in general at first sight. Individual group comparison indicated inconsistent results among groups, for instance, Turkish male and females used happiness and depression words almost similar performance just that Turkish males used both word groups more than Turkish females. Japanese and Spanish learners' performance is inverse proportion in respect of both gender and semantic comparison in using these antonym word groups. Japanese and Spanish males are identical in preferring happiness words much more than depression words unlike their female peers. Native English group performance show similarity except for females who tended to use depression words nearly twice as much as males.

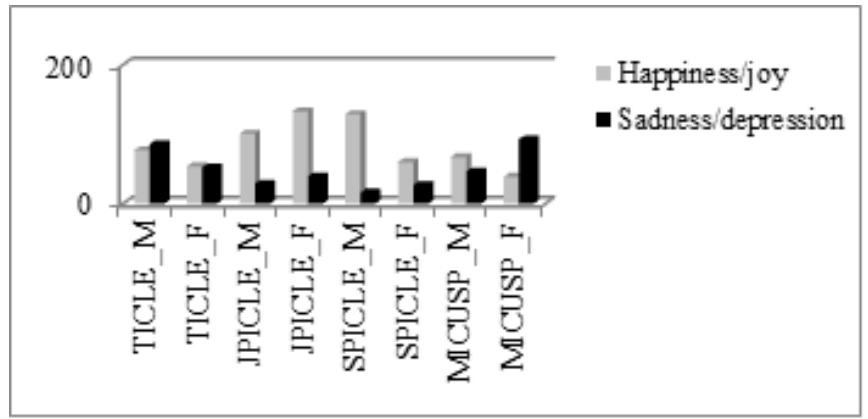

Figure 3. Distribution of Happiness/Joy and Sadness/Depression words among groups.

The word 'feel' is also considered as the major item of the present analysis as it is a term for emotions. All uses of 'feel' by female and male students were analyzed with all collocations that it was used together with in order to see gender usage. For instance, Turkish male students use verb 'feel' with negative words like pain, lonely, dirty, etc. and with positives like ready, comfortable whereas females use like feel bad, feel lonely, or feel bold, relieved as presented in Table 3. below:

Table 3. Collocation patterning of 'feel' by male and females in TICLE.

\begin{tabular}{|c|c|c|}
\hline \multicolumn{2}{|c|}{ TICLE_M total $n=18$} & TICLE_F total $n=13$ \\
\hline feel + & $\begin{array}{l}\text { Negative } \\
\text { pain } \\
\text { lonely } \\
\text { worried } \\
\text { unbearable }\end{array}$ & $\begin{array}{l}\text { Negative } \\
\text { regretful } \\
\text { unbearable } \\
\text { bad } \\
\text { sorry }\end{array}$ \\
\hline
\end{tabular}

\begin{tabular}{ll}
\hline TICLE_M total $\mathbf{n}=\mathbf{1 8}$ & TICLE_F total $\mathbf{n}=\mathbf{1 3}$ \\
\hline dirty & lonely \\
in trouble & insufficient \\
guilty & worse \\
Positive & Positive \\
ready & bold \\
comfortable & confident \\
not sorry & need \\
\hline
\end{tabular}

Although patterning of feel was done by different items, female and male students used it similar way in respect of negative and positive sense. Samples of usage of feel from a Turkish male and a female student as following:

(1)"for a test which they feel pain, uneasiness, suffering and are subjected to physical injury." (Male_TRKE2029.txt.)

(2)" When people sit and watch them they feel relaxed and enjoy themselves."'(Male_TRCU1029.txt)

(3)"..I felt worse as the days passing, since..."(Female_TRME3028.txt)

(4)"Sometimes we feel bold enough to get rid of these"(Female_TRCU1002.txt)

Contrarily, Japanese males used verb feel collocation with negative sense words more than females like feel uncomfortable, feel sad, etc. Also they use it in positive sense at similar amount as females (Table 4.). For instance:

Table 4. Collocation patterning of 'feel' by male and females in JPICLE.

\begin{tabular}{lll}
\hline JPICLE_M total n=29 & JPICLE_F total $\mathbf{n}=\mathbf{1 3}$ \\
\hline & Negative & Negative \\
uncomfortable & \\
strange & \\
sad & \\
lonely & \\
sorry & \\
hesitation & feel + & miserable \\
stress & & poor \\
dissatisfied & lonely \\
pity & distance \\
anxieties & & bitter \\
threatened & \\
tied & \\
upset & \\
necessity & \\
Positive & \\
& \\
safe & Positive \\
good & attachment \\
relaxed & up \\
& relieved \\
& & happy \\
& familiar \\
\hline
\end{tabular}

(5)"They may feel uncomfortable with insincere treatment" (Male_JPTM1002.txt)

(6) "..slow music that we listen to, we feel relax, quiet, cool" (Male_JPTF1011.txt)

(7) "..finished that performance, we all cried. I felt very happy.” (Female_JPKO1019.txt)

(8) “...but very pathetic. I felt so poor and it is difficult to..."(Female_JPKO2007.txt)

Spanish female and male EFL learners seem to use feel verb collocations similar to each other both semantically (negative/positive sense) and frequently as shown in Table 5 
below. Spanish male learners tended to use feel in more positive collocations than other male EFLs.

(9) "We have to try to feel satisfied with our possesions" (Male_SPMO2002.txt)

(10) "..they do not feel very confident, comfortable when....”(Male_SPMO5011.txt)

(11) "As a result, some soldiers feel useless.." (Female_SPMO.2006.txt)

(12) "...Do they feel the happiness and the freedom that .."(Female_SPM10009.txt)

Table 5. Collocation patterning of 'feel' by male and females in SPICLE.

\begin{tabular}{|c|c|c|}
\hline SPICLE_M & total $n=13$ & SPICLE_F total $n=14$ \\
\hline \multirow{4}{*}{ feel +} & Negative & \multirow{4}{*}{$\begin{array}{l}\text { Negative } \\
\text { dis- capacitated } \\
\text { uncomfortable } \\
\text { useless } \\
\text { (emotionally) offended } \\
\text { Positive } \\
\text { equal } \\
\text { free } \\
\text { pleasure } \\
\text { happiness } \\
\text { right }\end{array}$} \\
\hline & $\begin{array}{l}\text { sorry } \\
\text { captured }\end{array}$ & \\
\hline & Positive & \\
\hline & $\begin{array}{l}\text { satisfied } \\
\text { as a king } \\
\text { free } \\
\text { control } \\
\text { confident } \\
\text { protected }\end{array}$ & \\
\hline
\end{tabular}

In sum, lexical patterning of verb feel are in parallel structures as verb + noun and verb + adjective seem similar in all female and male corpora. Semantic structuring of feel in corpora reflected the tendency of using emotional words by female and males groups.

\section{Conclusion}

The overall evaluation of feeling and emotion words in English and their usage by female and male EFL learners and native English speakers is explained by research questions of the study as follows:

R.Q. 1: Is there statistical difference between male and female EFL learners in the use of feeling and emotion vocabulary?

There is statistical difference between male and female EFL learners. Male EFL learners from three different L1 background significantly used more feeling and emotion words in their argumentative essays in total than female EFL learners from three different L1 backgrounds. Turkish male EFL learners used more feeling \& emotion words than Turkish male EFL learners. Spanish male EFL learners used more feelings and emotions words than Spanish female learners. No significant difference between Japanese male and female EFL learners.

R.Q.2: What type of feeling and emotion vocabulary do male and female EFL learners prefer to use?

All EFL learners seem to prefer to use Happiness/Joy/Caring type of emotion words like: love, like, happy, hope, etc. in their argumentative essays rather than Anger/Hate, Sadness/Depression and Fear words. Anger/Hate related words are the least used type of emotion vocabulary by all EFL learners like: angry, mad, hate, annoying, etc.
Our findings on EFL learner investigation drew a contrary line to general emotion discourse views so far which were underlined by Dewaele and Pavlenko as "women are seen as more emotional than men and therefore they are more likely to be emotionally expressive.." (2002, p.275). In our case, L2 learner attitude at least in written discourse seem that emotion vocabulary are preferred by male EFL learners more than female EFL learners in their written productions. As a further suggestion, number of gender data can be enhanced to receive more generalizing results on emotion vocabulary usage by different sexes in written texts.

\section{Appendix}

\section{List of feeling and emotion vocabulary}

Anger/hate
Angry
Mad
Frustrated
Annoyed
Offended
Furious
Wild
Aggressive
Hostile
Irritated
Hate
Dislike

\section{Joy/Happiness/Caring}

Happy
Peaceful
Fine
Glad

Pleased

Satisfied

Cheerful

Friendly

Hopeful

Hope

Love

Like

Respect

Tolerant

Enthusiastic

Admire

Kind

Adore

Calm

Trust

Care

\section{Depression/Sadness}

Sad

Hopeless

Disappointed

Unhappy 


\section{Upset \\ Sorrow \\ Miserable \\ Depressed \\ Regret \\ Tired \\ Weak \\ Lonely \\ Hurt \\ Desperate \\ Worried \\ Shame \\ Sorry \\ Pain \\ Suffer}

\section{Fear}

Fear

Alert

Anxious

Unsure

Scare

Nervous

Afraid

Alarmed

Frightened

Horrified

Shocked

Terrified

(Adapted from Goldsmith, 2000 and Drummond, 2012)

Note: Words in the list were analyzed and calculated in their different forms (verb, adverb, adjective, noun), i.e.happy/ happiness/ happily, lonely/ loneliness, love/lovely/loving, etc.

\section{References}

[1] P. Baker, Using Corpora to Analyze Gender. London: Bloomsbury Academic, 2014.

[2] P. Baker Sexed Texts: Language, Gender and Sexuality. London: Equinox Publishing, 2008.

[3] S. M. Bloise and M.K. Johnson, "Memory for emotional and neutral information: Gender and individual differences in emotional differences," Memory vol. 2, 15, pp.192-204, 2007.

[4] J. Coates, Women, Men, and Language (2nd ed.). London: Longman, 1993.

[5] R.M.J. Catalan, "Sex differences in L2 vocabulary learning strategies, " International Journal of Applied Lingiistics Vol. 13, 1, pp. 56-77, 2003.

[6] J. F. Chen, Gender differences in Taiwan business writing errors. The Internet TESL Journal, Vol. 2, 10, 1996. Retreived from http://iteslj.org/Chen-GendrDifs/.

[7] J. Dewaele and A. Pavlenko, "Emotion vocabulary in interlanguage," Language Learning, Vol. 52,2 pp. 263-322, 2002.
[8] T. Drummond, "Vocabulary of emotions" 2012, retrieved from www.sba.pdx.edu/faculty/.../FeelingsList.pdf.

[9] R. Gholami, "Gender differences in task-based perfomnace of EFL students" IEEE Colloquium on Humanities, Science and Engineering Research, 2011.

[10] C. Graham, A. Hamblin, A. And S. Feldstein, "Recognition of emotion in English voices by speakers of Japanese, Spanish and English," International Review of Applied Linguistics in Language Teaching Vol. 39, pp. 19-37, 2001.

[11] S. Granger, "A bird's eye view of learner corpus research," in Computer learner corpora, second language acquisition and foreign language teaching, In S. Granger, J. Hong and S. Petch-Tyson, Eds., Amsterdam \& Philadelphia: John Benjamins, pp.3-33, 2002.

[12] O.T. Goldshmidt, O.T. and L. Weller "Talking emotions: gender differences in a variety of conversational contexts," Symbolic Interaction Vol. 23, 2 pp. 117-134, 2000.

[13] A. Haas, A. " Male and female spoken language differences: stereotypes and evidence," Psychological Bulletin Vol. 86, 3, pp. 616-626, 1979

[14] M. Hayati, S. Yazdani,. and M.Yarahnadi, M. “ Iranian EFL learners gender differences and their ability to refusal recognition," Indian Journal of Fundamental Applied Life and Sciences Vol. 4, 1PP. 326-337,. 2014.

[15] J. Holmes, "Women's Talk: The question of sociolinguistic universals In Language and Gender: A Reader," in J. Coates, ed. Oxford, 1, pp. 61-483, 998.

[16] A. Kilgariff,, P. Rychly, P. Smrz and D. Tugwell, "The Sketch Engine,” Proc EUROLEX 2004, Lorient, France, pp. 105-116, 2004.

[17] A.M. Kring and A. H. Gordon, A.H. "Sex differences in emotion: expression, experience and physiology," Journal of Personality and Social Psychology Vol. 74, 3 pp. 683-703, 1998.

[18] P. Kunsmann, "Gender, Status and Power in Discourse Behavior of Men and Women," Linguistik Online, Vol. 5, 1 2000. Retreieved from http://www.linguistikonline.de/1_00/KUNSMANN.HTM.

[19] Z. Koçoğlu, "The impact of gender difference on effective communication between learners of English and native speakers of English," H.U. Journal of Education, Vol. 28.2 pp. 279-292, 2013.

[20] W. Labov, The Social Stratification of English in New York City. Washington, DC. Center for Applied Linguistics, 1966

[21] R. Lakoff, Language and woman's place. New York: Harper \& Row Publishers, 1975.

[22] K. McLaren, (2013) Emotional Vocabulary List. 2013, Retrieved from http://karlamclaren.com/wpcontent/uploads/2010/11/Emotional-Vocabulary.pdf.

[23] Michigan Corpus of Upper-level Student Papers, Ann Arbor, MI: The Regents of the University of Michigan, 2009.

[24] M.L. Newman, C.J. Groom, L.D. Handelman, L.D. and J.W. Pennebaker, "Gender differences in language use: an analysis of 14,000 text samples," Discourse Processes Vol. 45, pp. 211236, 2008. 
[25] E. Rintell, "But how did you feel about that? The learner's perception of emotion in speech" Applied Linguistics, Vol. 5, 255-264, 1984.

[26] E. Rintell, "That reminds me of a story: The use of language to express emotion by second language learners and native speakers," In The Dynamic Interlanguage: Empirical Studies in Second Language Variation, M. Eisenstein, ed. New York: Plenui m Press, pp. 237-57, 1989.

[27] A. Shehadeh, "Gender differences and equal opportunities in the ESL classroom” ELT Journal, Vol.53, 4, pp.256-261, 1999.

[28] P. Trudgill, Sociolinguistics: An Introduction to Language Use and Society. Middlesex, UK: Penguin, 1974.

[29] I. Van Baalen, Male and female language: growing together? 2001. Retreieved from http://www.let.leidenuniv.nl/hsl_shl/van\%20Baalen.htm.
[30] R. Xiao and H. Tao, "A corpus-based sociolinguistic study of amplifiers in British English," Sociolinguistic Studies, Vol. 1, 2, pp. 241-273, 2007.

[31] S. Zafar and K. Meenakshi, "Individual Learner Differences and Second Language Acquisition: A Review" Journal of Language Teaching and Research, Vol. 3, 4, pp. 639-646, 2012.

[32] S. Zeynali, "Exploring the Gender Effect on EFL Learners' Learning Strategies" Theory and Practice in Language Studies, Vol. 2, 8, pp. 1614-1620, 2012.

[33] H. Zhuanglin, Linguistics: An Introduction. Beijing: Peking University Press, 1989. 